\title{
THE CELLULAR BASIS OF MICROVESSEL RESTRICTION AND NEOMUSCULARIZATION IN PULMONARY HYPERTENSION
}

\author{
Rosemary C. Jones \\ Department of Anesthesia, Massachusetts General Hospital, Boston, Massachusetts, USA
}

\section{SUMMARY}

- Pulmonary hypertension is a common and serious condition, either as a primary event or secondary to other injury. In its clinical form there is always a restrictive lesion caused by vascular cell proliferation. This narrows the lumen of vessels throughout the lung but especially ones forming the microcirculation, the smallest vessels that lie adjacently to the capillaries. In addition, contractile cells develop in segments $v$ /here normally these cells are absent (neomuscularization). As these cells form elastic laminae and organize into intimal and medial layers, microvascular segments that resemble capillaries in wall structure are converted into thick-walled vessels. To analyze the cellular basis of this we have developed a model of restrictive pulmonary hypertension in the rat breathing high oxygen at normobaric pressure. Vascular changes begin within hours of injury and progress until virtually all microvessels are affected. Currently, little is known of the mediators that act as signal molecules but it is likely that ones released by inflammatory and vascular cells stimulate chemotaxis, proliferation and expression of contractile organelles, as well as secretion of the matrix proteins. Light microscopy studies and quantitative methods of analysis provide a broad understanding of the nature and extent of wall reorganization within the microvessel network. High resolution studies, including the use ofimmunogold techniques, are critical to identify cell phenotype during the early stage of wall changes, and, later, the type of filament proteins expressed as cells switch phenotype by acquiring contractile organelles.

\section{INTRODUCTION}

- Only a few millimeters in length, but numerous, the microvessels are a critical site of restriction to blood flow in pulmonary hypertension. Myriads of these vessels regulate flow to and from the capillary network in the lung's alveolar region, where most gas exchange occurs. In the adult human lung about 300000000 alveoli are each supplied by 1000 capillary segments.

In the normal lung, these vessel segments adjacent to capillaries (pre- and postcapillary segments) are appropriate in size and structure for anatomic level, but injury changes this, thickening their wall by increasing cell mass and number. The result of cell proliferation, in excess of the need for cell replacement, is lumen narrowing. When widespread, such changes effectively block the microvessels and are the structural basis of a maintained rise in pulmonary vascular resistance (PVR) and pulmonary arterial pressure (PAP). Constriction and hyperreactivity, each responsible for a transient rise in PAP, often are superimposed on a structurally restricted bed. In addition to proliferating, the newly developing microvascular cells express contractile organelles, leading to the development of smooth muscle in previously nonmuscular segments of the circulation (neomuscularization). This review represents an overview of our experimental studies directed to understanding the basis of this wall remodeling at the cellular and molecular level. 
The focus of this review is microvascular wall remodeling in the adult lung. Similar changes restrict the microvascular bed in (i) primary pulmonary hypertension, including its idiopathic forms (arterial and venous) as well as chronic thromboembolism and perivenous obliteration, and (»') secondary pulmonary hypertension due to heart-lung disease, through a passive rise in pulmonary venous pressure, a reactive response to high flow, or vaso-occlusive disease (1). Vascular restriction also may occur in utero, or after birth, where changes are superimposed on and alter the template of normal vessel growth (2). The several other vascular lesions that are associated with lumen occlusion by wall cells, organizing thrombi, or intimal fibrosis, as in plexiform and angiomatoid lesions, necrotizing arteritis, and perivenous fibrosis, are discussed elsewhere (3 -5).

It is important to note that although it is narrowing of the microvessels that so restricts the vascular bed, large arteries also narrow in the hypertensive lung (6-11). In these vessels the normally thick muscular wall is thickened further by proliferation of endothelial cells, smooth muscle cells (SMC) and fibroblasts, and by the increased deposition of collagen fibrils, as well as by other extracellular matrix components. Similar changes occur along the loops of increasingly smaller vessels that drain to and from the microvascular segments. Whether in these larger vessels the changes reflect a greater hemodynamic load that is independent of microvascular injury, or occur secondarily to microvascular injury and increase in pressure, is not fully understood. Wall remodeling in these vessels, as in the microvessels, is likely effected by processes that resemble ones in systemic vessels. That is (i) the sensing of signals that reflect hemodynamic conditions, (ii) the transduction of signals within and between cells, and (iii) the synthesis and release of mediators for cell growth, death, migration and matrix deposition (12). In lung vessels of all sizes, however, cell labeling studies demonstrate an effect before PVR and PAP increase, indicating an early response to mediators for vascular cell growth.

In considering how microvessels are restricted, it is evident that in addition to the proliferative changes described here, the lumen may be obliterated, blocked, or narrowed by a thrombus or by cell swelling $(1,7)$. In addition, the lumen may be narrowed by wall contracture or compression, as in interstitial fibrosis. Contracture, mediated by an endothelium-dependent remodeling process, results from a chronic decrease in blood flow (13). In the microvessels especially, the extent of the injury and differences in the susceptibility of cells determines whether a segment is obliterated or remains patent. If injury is severe, and necrosis and cell loss lead to wall obliteration, the structural changes are probably irreversible. If cell swelling or hypertrophy and hyperplasia lead only to lumen occlusion, lumen patency may be restored. High blood flow through a restricted bed, however, will further injure the artery wall and increase PVR, and so potentiate structural changes (14). The extent to which the residual vascular bed is stiff or hyperreactive (2) reflects wall changes that result from an imbalance in the synthesis and degradation of matrix proteins, and from the expression of endothelial cell-derived mediators for SMC, as well as from SMC function $(12,15)$.

\section{NORMAL VESSEL STRUCTURE AND TECHNIQUES TO ASSESS WALL REMODELING}

- In the normal lung, along any vessel pathway from the hilum to periphery, as vessels branch into segments and become increasingly smaller in diameter, wall structure changes (16-18). Thus, the arrangement of cells and matrix components is different in proximal and distal segments of a single vessel pathway, and not necessarily the same at the equivalent branch-point of different pathways. This structural diversity must be considered when assessing wall changes in pulmonary hypertension. For ease, the wall structure of the microvessels is described here in relation to that of vessels throughout normal lung.

\section{- Normal vessel structure}

In human adult lung, conventional pulmonary artery branches run with airways and share a single connective tissue sheath. Additional artery branches arise independently, and supply adjacent alveoli $(16,17)$. These are termed "supernumerary" branches. At all levels, they are more numerous than conventional branches, and their number is greatest distally. Despite being more frequent they are narrower, however, and so their total cross-sectional area is less than that of conventional arteries. The pulmonary venous bed also has conventional and supernumerary branches (19). While the number of conventional veins and arteries is similar, the number of supernumerary veins is greater.

Near the hilum, where in cross-section the arterial wall has SMC and at least four additional elastic laminae inbetween the internal and external laminae, the vessels are termed elastic (16). Further distally, where the central laminae decrease to leave SMC between only an internal and an external laminae, the vessels are termed muscular (M). In these segments, the thickness of the medial muscle layer decreases as the vessel diameter decreases to about $500 \mathrm{Lim}$ ED (external diameter), the thickness of the media here representing about 5\% of the ED. At the entrance to the acinus, in vessels 250-500 p.m ED, the medial thickness increases, representing up to $20 \%$ of the ED. These segments represent the so-called "resistance segments", where wall thickness is relatively high for vessel diameter. Within the acinus, where the complete layer of medial SMC becomes incomplete, and spirals to form only a crescent in the wall (Fig.l), the vessels are termed partially 
muscular (PM). These segments have a medial SMC layer between an internal and external elastic lamina on one side of their wall, and only a single lamina and no SMC on the other. Distally, where the medial muscle layer disappears completely from the wall (Fig.l), the vessels are termed non-muscular (NM). Some of these segments have only an elastic lamina adjacent to endothelium (16). Others that are amongst the smallest of these segments $(>20<25$ (im in diameter) have no elastic lamina (20). Because a similar arrangement of wall muscle is seen on the venous side it is difficult to identify small arteries from veins by wall structure alone. The larger veins $(>100 \mathrm{p}, \mathrm{m})$ are readily identified from arteries by their position and thinner wall.

In other mammalian species, including the rat (the species used in the experimental studies discussed here) supernumerary vessels are present and the distribution of intraacinar vessels is similar to that described for human lung in that M, PM and NM segments are present $(1,6,8)$.

From the hilum to lung periphery five cell types form the vessel wall in normal lung: the endothelial cell, the SMC and its two precursor cells, the intermediate cell and pericyte, and the adventitial fibroblast. Only the endothelial cell is found throughout the vascular bed, and precursor SMC are found only in the microvessels. In relation to matrix components, especially elastic laminae, the arrangement of cells within the vessel wall is characteristic. In the microvessels, the presence of cell types varies with the segment: endothelial cells lie in- ternally to a single or internal lamina and form the vessel intima. And, in segments where they are present, precursor cells lie beneath the endothelium within the intima, SMC lie between an internal and external lamina and form the media, and fibroblasts lie abluminally to a single or external lamina and form the adventitia. The wall of some segments that have no lamina consists only of endothelial cells and basement membrane. These have a similar wall structure to capillaries but are larger in diameter.

Reconstruction studies have shown that the single axial artery that enters the acinus divides into two tapering segments that branch with several generations of alveolar ducts before dispersing into a capillary network in the alveolar wall (21). Normally, along the axial pathway, and in the NM segment adjacent to the endothelium, the processes of precursor cells form a thin attenuated layer (21-23). When most proximal, i.e. at the level of the second generation of alveolar ducts, these cells express a SMC phenotype (21). Further distally lie intermediate cells, so-called because they are intermediate in structure and location between SMC and pericytes. Like SMC they are enveloped in their own basement membrane but like pericytes they possess few filaments or dense bodies $(21,23)$. In response to injury, intermediate cells become SMC by developing additional contractile organelles $(9,20,22)$. It has been suggested that in the smallest NM segments, pericytes, which are increasingly considered a contractile cell $(24,25)$, similarly form a precursor cell population $(9,20,22)$.

\section{MUSCULAR PARTIALLY NON}

MUSCULAR MUSCULAR
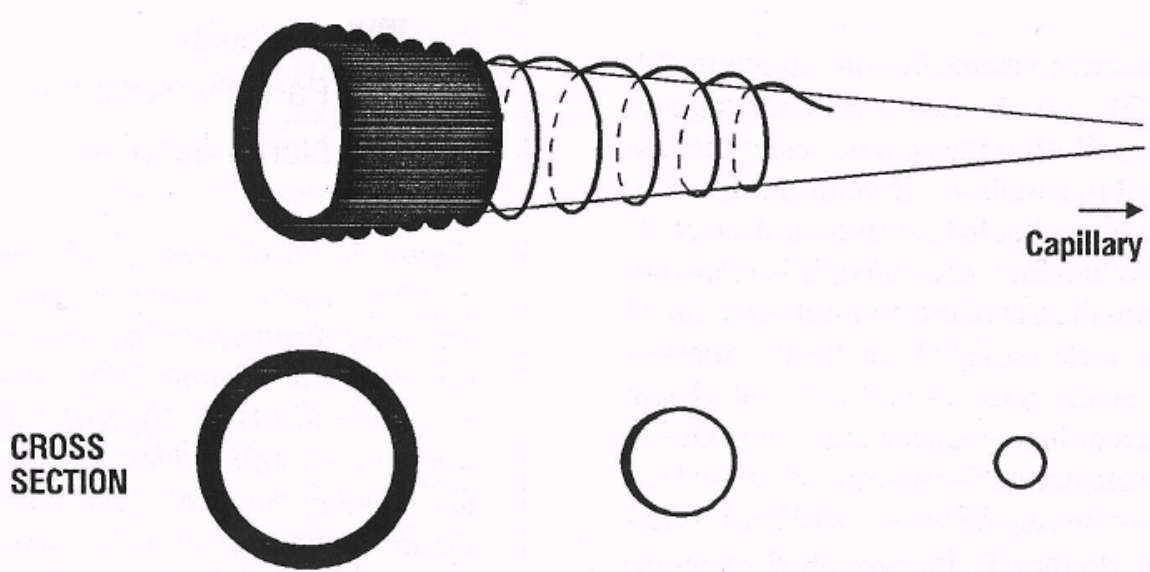

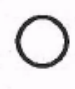

Figure L Illustration of pulmonary artery wall showing arrangement of muscle. Along any one pathway from the hilum to lung periphery the structure of the wall changes as the muscle coat diminishes to form a spiral and then disappears from the wall. In cross-section the muscle layer may be complete (a muscular artery), incomplete (apartially muscular artery) or absent (a non-muscular artery). (From Ref. 17, with permission.) 
- Quantitative analysis of pulmonary vessels, with emphasis on the microvessels

The normal vessel wall is constantly remodeled by homeostatic mechanisms. Wall remodeling in response to injury is an adaptive process in which mediators released by injured vascular cells, and by inflammatory cells, change proliferation rates and matrix production. Hemodynamic forces also determine lumen size. In response to long-term changes in flow the endothelium, sensing change in shear stress, releases mediators that remodel the vessel wall, increasing lumen size to maintain an appropriate level of shear stress (12).

Morphometric techniques applied to vessel populations in the normal and hypertensive lung establish the nature of wall changes, their extent, and precise location. For the purpose of this analysis, all patent vessels and the airways must be fully distended. For light microscopy studies, a radio-opaque substance such as barium sulfate gelatin injected at a high distending pressure $(100 \mathrm{~cm} \mathrm{H}, \mathrm{O})$ will fill patent vessels. Either the pulmonary arteries or veins can be injected since the injection medium does not cross the capillaries. The airways are then distended with fixative $(23 \mathrm{~cm} \mathrm{H}, \mathrm{O})$ to allow each vessel to be identified by its position in relation to airway structures. An alternative method that is particularly useful for ultrastructural studies (23) is to distend both the vessels and airways with fixative, also at $100 \mathrm{~cm} \mathrm{H}, \mathrm{O}$ and $23 \mathrm{~cm} \mathrm{H}, \mathrm{O}$, respectively. The presence of erythrocytes washed from the arterial to the venous side of the circulation assists in identifying small arteries from small veins. If the vascular bed cannot be distended, then the area of medial muscle in the wall can be assessed to provide an index of change, but only after airway distention and "landmarking" can a vessel segment be precisely located within the network.

In our studies, we characterize vessels by wall structure (M, $\mathrm{PM}$ or $\mathrm{NM}$ ) and size (ED), and use their accompanying airway as a landmark (Fig.2). Within the acinus, vessels are associated with respiratory bronchioli, or alveolar ducts, or lie within alveolar walls. The latter, including alveolar duct, comprises the microvessels. When fully distended, it is relatively straightforward to measure the ED of these vessels and, for $\mathrm{M}$ and PM ones, the medial thickness (MT), i.e. the thickness of the muscle layer between the internal and external elastic lamina, to obtain an index of lumen narrowing. This value is related to vessel size by calculating the percent $\mathrm{MT}(\% \mathrm{MT}=$ 2 x MT x 100/ED for M vessel segments or 1 x MT x 100/ED for PM vessel segments). As the MT increases and vessel diameter is reduced, the percent MT increases. A further index of microvascular restriction is obtained by the ratio of filled arteries to alveoli, providing an assessment of patent vessels that is independent of the degree of airway distention.
The distribution of organelles within cells, and the arrangement of cells within the vessel wall, identifies cell phenotype distinguishing endothelial cells from adjacent precursor cells, precursor cells from medial SMC, and adventitial fibroblasts from contiguous interstitial cells (20). While similar cell types are found in vessel walls in the normal and hypertensive lung, additional cell types are recognized in the latter in relation to wall remodeling $(1,20)$.

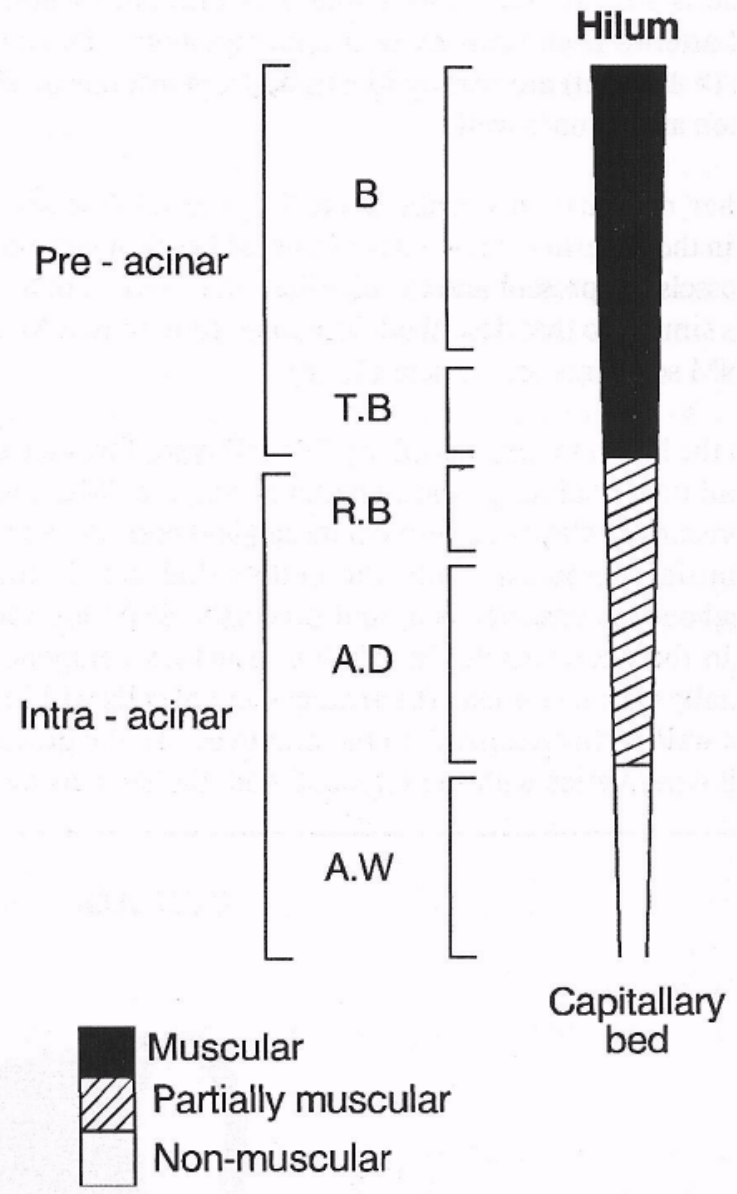

Figure 2. Illustration of arrangement of pulmonary artery wall structure in relation to accompanying airway level (bronchiole [B], terminal bronchiole [TBJ, respiratory bronchiole [RB], alveolar duct $[A D]$ and alveolar wall $[A W])$. Typically, the resistance vessels, where vessel wall is thick for vessel diameter (see text) are found at the level of the TB. Near the entrance to the acinus the vessel wall changes from muscular to partially muscular. This may occur at the level of the $R B$ (as shown) or more distally, at the level of the $A D$. Further distally along the pathway the wall changes to non-muscular. This may occur at the level of the AW (as shown) or more proximally, at the level of the $A D$. 


\section{EXPERIMENTAL STUDIES OF MICROVESSEL WALL REMODELING IN PULMONARY HYPERTENSION}

- In vivo models offer a unique opportunity to investigate the cellular basis of microvessel wall remodeling in a system in which crucial cell-matrix interactions are maintained (26). While breathing either a high or low oxygen, tension leads to widespread microvessel restriction and to the development of pulmonary hypertension. The pattern of restriction as shown by fractal analysis is not the same for the two injuries, restriction of the smallest vessels being greater in the hyperoxic lung where an inflammatory component is found $(8,27)$. The effect of hypoxia on vessel wall remodeling, a metabolic injury with little evidence of an inflammatory response, has been well studied $(9,26)$. Our interest in the effect of hyperoxia started with our studies of vascular changes in the lungs of patients dying of the adult respiratory distress syndrome. Over the course of days to weeks, these patients, who receive high oxygen tensions, develop pulmonary hypertension with a vascular bed that typically at first responds to a dilator but later becomes unresponsive (28). Vessels throughout the lung are affected $(7,29)$. Because of the reported effects of high oxygen tension on the lung, especially its damaging effect on capillaries, we studied the microvessels under such conditions to establish if injury would lead to pulmonary hypertension. During the first days of breathing high oxygen alveolar-capillary membrane cells show marked injury, and pulmonary edema is common. Adaptation occurs between Day 3 and 4, and the edema largely resolves. This allows the development of a model of chronic vessel injury.

\section{- The cellular basis of microvessel restriction}

By Day 7 of hyperoxia, wall thickening and right ventricular hypertrophy (RVH) are established and PAP increased (control, $\bullet 17-18 \mathrm{~mm} \mathrm{Hg}$; hyperoxia, $-26 \mathrm{~mm} \mathrm{Hg}$ ) and the vascular bed is more reactive to challenge $(6,30)$. Interestingly, although the vascular bed as a whole is hyperreactive, reflecting mostly the response of the microvessels, the walls of vessels at the entrance to the acinus are stiff, at least in part because of extensive collagen deposition $(30,31)$. Vascular injury, including a fall in the ratio of filled arteries to alveoli (a reduction of about one third by Day 7), progresses with time. By 4 weeks, in addition to wall thickening, the wall changes include lumen occlusion and obliteration (8). Both RVH and PAP are further increased (hyperoxia, 45-70 $\mathrm{mm} \mathrm{Hg})(7,8)$. In the hyperoxia-adapted lung, despite careful weaning (-10\% less oxygen daily) over the course of one week, the challenge of relative hypoxia caused by return to breathing air leads to further injury (8). An increase in RVH early during the weaning period indicates a corresponding rise in PVR, and although RVH later falls, as does PAP (hyperoxia, $32 \mathrm{~mm} \mathrm{Hg}$ ), neither regain the normal value in the 8-week "recovery" period that we studied in these animals (7).
The extent of restriction in the hyperoxic lung after 4 weeks is well illustrated by arteriography (Fig.3a,b). There is a loss of small arteries filled with barium, and narrowed central and axial arteries. Venograms show that the small veins (about $150 \mathrm{Jim}$ ED) are similarly affected (32). Histologically, this pruning is seen to include both obliterative and occlusive lesions (8). Many vessel remnants indicate continuing cell injury and the failure of these segments to adapt to hyperoxic conditions. Lumen narrowing is widespread (Fig.4a,b) and there is intimal accumulation of monocytes and hyalinization of the media (8).

In the normal rat lung, about half the number of vessel segments at the level of alveolar ducts, and most in alveolar walls have no medial SMC (Fig. 5). This provides clearly defined segments in which to follow muscle development in response to injury. Quantitative studies (8) demonstrate a significant increase in the percent MT of arteries, and a shift to vessels with medial muscle at the expense of NM ones (Fig.5). After 2 weeks in air, thinning of the percent MT indicates regression although paradoxically there is a further increase in the number of alveolar wall and duct segments with muscle (Fig. $6,7)$. After 8 weeks in air, the number of vessels with muscle is below that after 2 weeks, and is less than at the end of hyperoxia, but is still greater than in normal lung (Fig. 6). In some animals, increased filling on the arteriogram suggests that lumen patency is restored to some vessels, indicating those in which the lumen was occluded by cell swelling (8).

\section{- Cell proliferation}

By a standard pulse labeling technique in which $\left[{ }^{3} \mathrm{H}\right]$ thymidine is incorporated into vascular cells entering the synthetic phase of mitosis, we analyzed a series of time points to assess their proliferation during the course of wall remodeling, i.e. on days $1,4,7,10$ and 28 , counting the number of labeled cells per 1000 cells of the same type (33). This technique does not indicate the full extent of proliferation but rather the time when it peaks. The extent and timing of these bursts of activity is different for the same cell type at different levels within the lung, e.g. for endothelial cells in the microvessels or at the hilum, and for cell populations at the same level, e.g. for endothelial cells, SMC, precursor cells or fibroblasts in the microvessels.

In normal lung, few microvascular cells label (33). Of these, most are fibroblasts and SMC, a few are endothelial cells and none are precursor cells. At the start of hyperoxia (Day 1) no microvascular cells are labeled, but by Day 4 the index is high for all cell types except the medial SMC. It is the labeling index of the fibroblast, however, that is strikingly increased (-20 fold)., While a high level of labeling then persists in these cells it does not again achieve this peak value. Most of 

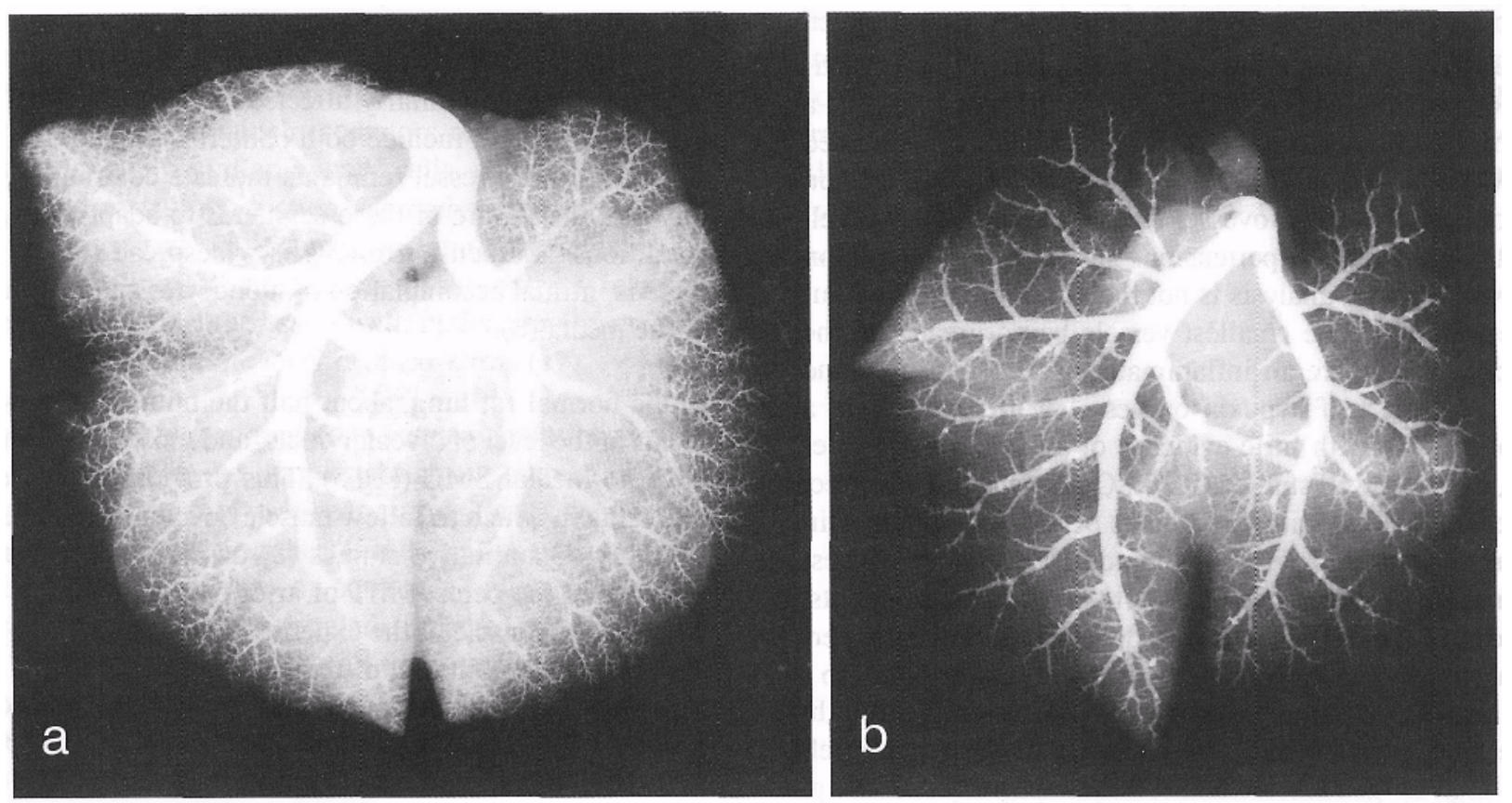

Figure 3. Rat pulmonary arteriograms (original magnification, x 2.5) illustrating restriction of the vascular bed in the hypertensive lung. (From Ref8, with permission), (a) Normal lung: filled vessels (>160[im ED) are discerned as separate lines and ones (<J60 pm ED) as a background haze. The background haze is dense and uniform, (b) Hyperoxic lung (87\% 0, for 28 days): loss of the background haze denotes non-filled small vessels. Narrowed axial and lateral branches are also evident.
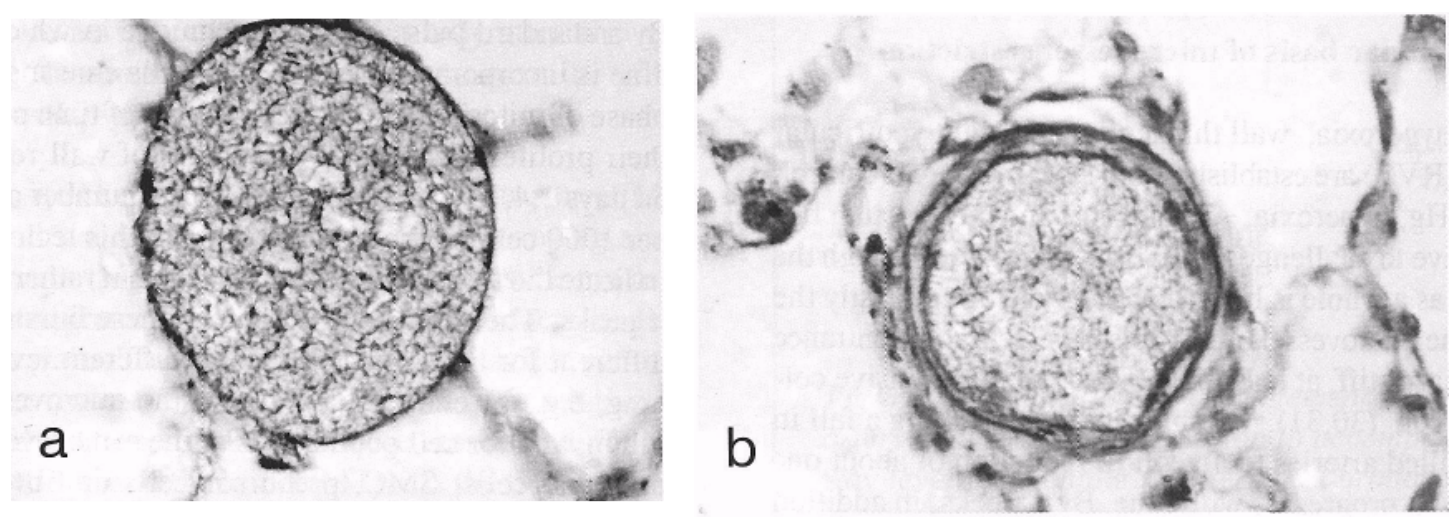

Figure 4. Rat alveolar wall arteries (4 Vim sections stained with MEVG). In both vessels the lumen is distended with barium-gelatin sulfate.(From Ref 8, with permission), (a) Normal lung: thin-walled vessel with a single elastic lamina (72 $\mathrm{H} / \mathrm{n} \mathrm{ED}, \mathrm{x} 640)$. Alveolar wall vessels typically have this wall structure in normal lung, (b) Hyperoxic lung $\left(87 \% \mathrm{O}_{2}\right.$ for 28 days): a muscular artery with a well-developed media between an internal and external elastic lamina (53 jJ.ni ED, x 640). In pulmonary hypertension, alveolar wall vessels typically develop muscle cells that first lie internally to a single elastic lamina, and then are separated from the endothelium by the development of a second elastic lamina. The first lamina forms the external lamina within the vessel wall. The lamina that separates the newly developed contractile cells from the endothelium forms the internal one. 
Alveolar duct vessels
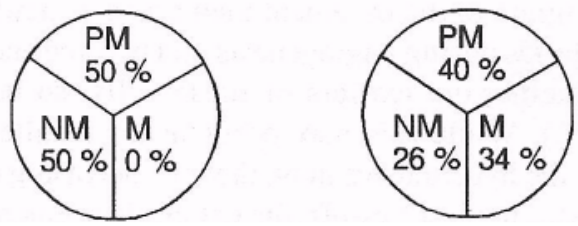

Alveolar wall vessels

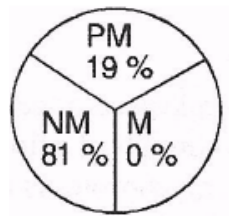

DayO

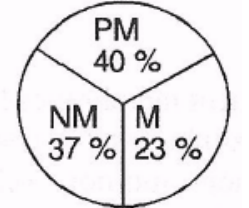

Day 28

Figure 5. Percent of non-muscular (NM), partially muscular (PM) and muscular (M) vessels (<100 fjm $E D)$ associated with alveolar ducts and in the alveolar wall. In hyperoxic pulmonary hypertension as vessel walls remodel the normal distribution of alveolar duct and wall vessels (Day 0) shifts (Day 28), as vessels with a medial muscle layer ( $M$ and $P M$ vessels) increase at the expense ofNM ones (ptf 0.001 for both airway levels).

the labeled flbroblasts are identified around vessels with no elastic lamina.

The labeling index of the endothelial cell increases on Day 7 ( 10-fold) and then remains high. Labeled precursor cells are present on Day 4 when the highest labeling index occurs (-40fold increase). While the relative number of proliferating cells is higher for the precursor cells than for flbroblasts the absolute number of proliferating flbroblasts is the greater (8). In the lum epon sections used for these studies it was not possible to identify cell phenotype. Despite a steady increase over time in the number of cells in the same location as the precursor cells, labeled precursor cells are not identified in large numbers after this time, raising the question of their origin. Labeled microvascular SMC are not identified until Day 28 and the extent of labeling is minimal compared to that for other cell types. After weaning and return to breathing air, the labeling index for each cell type is above normal but less so than during the first days of hyperoxia (33).

Clearly, in the microvessels of the injured lung, SMC present between an internal and external elastic lamina are relatively slow to divide, as are the existing precursor cells lying internally to an elastic lamina. A remarkable feature is the high labeling of fibroblasts as these cells are recruited to and align

Alveolar duct vessels
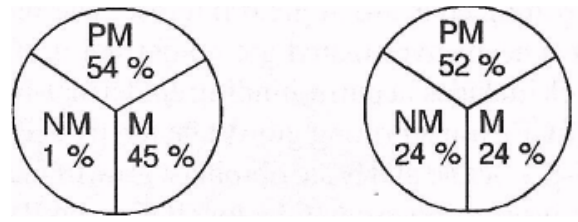

Alveolar wall vessels

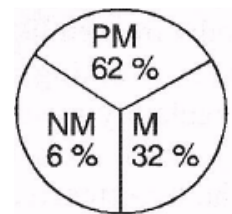

2 wks air

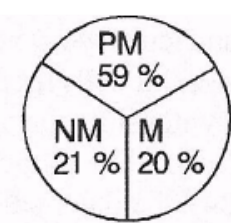

8 wks air
Figure 6. Percent of non-muscular (NM), partially muscular (PM) and muscular (M) vessels associated with alveolar ducts and in the alveolar wall. After weaning and return to breathing air, the number of vessels with muscle increases at the expense ofNM ones (ptf 0.001 for both airway levels when compared to the distribution of vessels in normal lung). After 2 weeks in air, in response to the relative hypoxia of air, the number of alveolar duct and wall PM and $M$ vessels is higher than at Day 28 (increasing from 40 to $54 \%$ and from $34 \%$ to $45 \%$; and from 40 to $62 \%$ and from $23 \%$ to $32 \%$ for these vessel populations respectively, comparing values after 2 weeks in air with those shown for Day 28 in Fig.5). After 8 weeks in air vessels with muscle persist, although their number decreases significantly $\left(p \% \%^{2} 0.001\right.$ for both airway levels when compared to the distribution of vessels after 2 weeks in air). In the most distal region of the lung, however, $P M$ and $M$ vessel numbers remain similar to those at the end of hyperoxia (being 40 and $59 \%$ and 23 and $20 \%$ for alveolar wall vessel populations respectively, comparing values after 8 weeks in air with those shown for Day 28 in Fig 5).

around vessel walls. It is particularly to microvessel segments in regions of the interstitium disrupted and expanded by edema that these cells migrate. As they are incorporated into the vessel wall by the formation of an elastic lamina along their abluminal edge $(20,22)$ this effectively converts them into a precursor cell layer beneath the endothelium. Thus, it is the recruitment and proliferation of flbroblasts that contributes most to the increasing number of precursor cells appearing within the walls of the smallest microvessels in pulmonary hypertension. 
To further understand the proliferative response described here, and ultimately to devise ways to prevent it, the growth factors expressed by lung cells are of great interest. The major families that have been investigated are epidermal growth factor $(\mathrm{EOF})$, which includes heparin-bindingepidermal-like growth factor (HB-EGF), transforming growth factor- $\mathrm{p}$ (TGF-P, , TGF$\mathrm{P}_{2}$ and TGF- $\mathrm{P}_{5}$ ), acidic and basic fibroblast growth factor (aFGF and bFGF), insulin-like growth factor (IGF I and II), plateletderived growth factor (PDGF A and B) and tumor necrosis factor-a (TNF-a). Inflammatory cells (alveolar macrophages, monocytes and leukocytes) and mast cells are their likely source as are the vascular cells themselves (15). Working in concert, these cells synthesize and release regulatory molecules that act through autocrine, paracrine, or, in some cases, juxtacrine pathways (34). To date, studies of the hypertensive lung, although rather limited, indicate that ligands from each family play a role (6,35-42). Further studies are needed to identify temporal and spatial changes in gene expression for these ligands and their receptors. In addition, immunocytochemical studies to identify sites of biologically active protein are needed. How cells switch on and off their response in a tissue saturated with growth factors is an intriguing question, involving the effect of these factors on interactions between cellular and matrix components, via adhesion molecules (see 43,44).

\section{- Neomuscularization (transdifferentiation of non-con- tractile to contractile cells)}

Neomuscularization of the vessel wall includes the development of a new layer of intimal contractile cells and organization of these cells into a medial layer $(1,20)$. Cells express filament proteins and assemble an intracellular filament system (Fig.7a,b) via a process of phenotypic switching, or transdifferentiation, as they adapt to their environment in the vessel wall $(20,45)$. The development of contractile organelles follows cell proliferation and organization within the wall. Reconstruction of vessel profiles shows that new contractile cells appear only in the wall of NM segments of the microcirculation, i.e. they do not develop internally to a medial layer (20).

In the hyperoxic lung, intermediate cells quickly produce filaments and dense bodies (by Day 3). Often these filaments run parallelly to the longitudinal orientation of the cell and occupy the adluminal edge. Filament production in fibroblasts is delayed until about Day 7. Only after their alignment around a vessel, possibly in response to a chemotactic factor such as endothelin-1 being released by injured endothelial cells (46), and their incorporation into the wall, do these cells express filaments in large numbers. How these cells relate to the contractile interstitial cell and myofibroblast typical of the interstitium in normal lung, or in response to injury, is not yet established (47-49). Nor is it yet known if the fibroblasts that form the vessel wall evolve into contractile cells that are pericytic, or if indeed they first become pericytes and then develop contractile organelles. In rat mesenteric vessels, fibroblasts migrate to the basement membrane of newly developing capillaries during angiogenesis and become enclosed in basement membrane leaflets of these cells, so becoming pericytes (50). While this may occur in the smallest vessel segments in the hypertensive lung, thereby increasing the number of pericytes in these vessels, the pattern in segments where fibroblasts align is more complex since it involves the formation of an elastic lamina before the expression of contractile organelles.

New basement membranes form around vascular cells following their proliferation. In general this consists of a fine network of collagenous and non-collagenous glycoproteins that separates the cell from the surrounding matrix, acts as a selective barrier, and stimulates cell differentiation, morphogenesis and movement (51). The main components, type IV collagen and laminin, self-assemble into a structural network to which other components, such as heparan sulfate proteoglycan (perlecan), chondroitin sulfate proteoglycan, entactin (nido-gen), tenascin and fibronectin, bind $(51,52)$. Each of the component of the membrane is known to influence cell-matrix interactions. These include cell adhesion, spreading, polarization, movement, and proliferation, as well as phenotype. While the components of the membrane change in pulmonary hypertension (52) little is yet known of the molecular components of the basement membrane of individual vascular cell types. Its structural organization and its function as a source of cell signaling molecules has been discussed by Yurchenco and O'Rear (53) and by Vlodavsky and colleagues (54). While it may be expected that growth factors stored in the basement membrane will exert a local effect on cells, it is increasingly clear that this interaction is regulated by matrix components (55).

The development of a first or second elastic lamina, along the abluminal and adluminal edge of cells respectively, defines a new intimal or medial layer in the vessel wall. At this site, as for basement membrane, little is known of the assembly of the laminae. In other tissues, elastic fiber microfibrils aggregate in parallel arrays often occupying Moldings of the cell membrane $(56,57)$. These act as a scaffold where elastin is deposited as small clumps of amorphous material within the aggregates which then coalesce to form elastic fibers. Tropoelastin, secreted by cells into the surrounding matrix, accretes onto the surface of the developing elastic fiber where it interacts with the microfibrils and is aligned for cross-linking. Recently, three molecules have been identified as microfibril components: (/') $31 \mathrm{kD}$ microfibril-associated glycoprotein, (») 350 $\mathrm{kD}$ glycoprotein, fibrillin $(58,59)$, and $(\mathrm{Hi}) 35 \mathrm{kD}$ protein with amine oxidase activity. Further studies are needed to analyze these components of the laminae and their assembly during wall remodeling in the lung microvessels. 


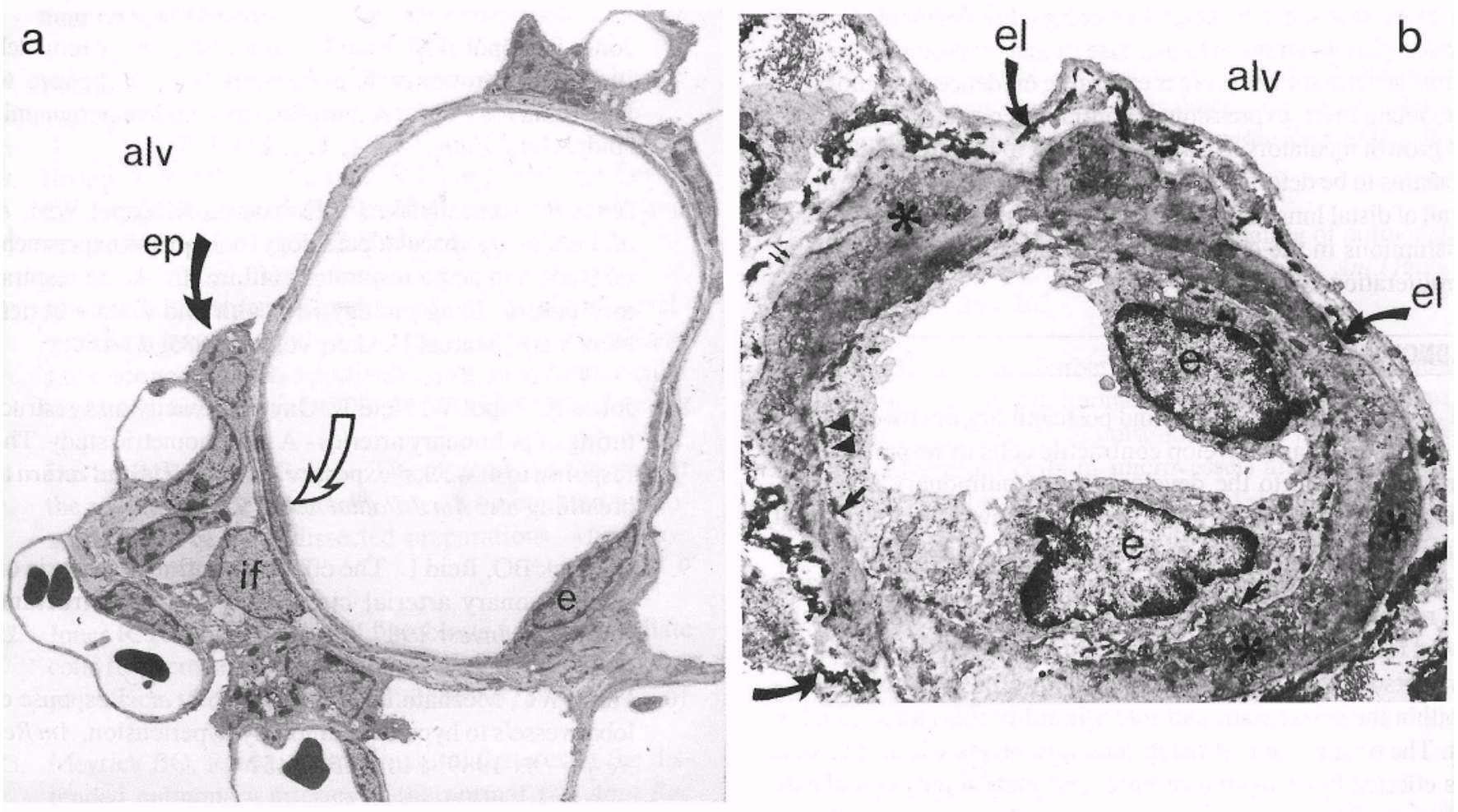

Figure 7. Transmission electron micrographs of alveolar wall vessels, (a) Normal lung: non-muscular vessel (25 jMn ED, x 3954); endothelial cell (e), interstitial fibroblast (if), epithelial type 2 cell (ep). At higher magnification, an additional cell (at open arrow) was classified as an intermediate cell (not shown). (From Ref20, with permission), (b) Hyperoxic lung - vessel (J5.5fJ.rn ED, х 8750):with contractile cells forming a sub endothelial cell layer (28 days at 87\% $\mathrm{O}_{2}$ ). Subendothelial cell process (*) lie adluminally to a well-defined electron-dense elastic lamina (el) and abluminal to endothelial cells (e). Basal lamina is evident along the abluminal cell edge (small arrows), and focal elastin deposits adluminally (single arrowheads). The newly developed cells are triangular with the features of a contractile cell; microfilaments are heavily distributed throughout the cell process at the top, less in the process in the lower region of the wall, and, at high magnification, dense bodies are seen. Interstitial fibroblast (if), alveolus (alv). (From Ref. 20, with permission)

The current lack of detailed knowledge of how the new cells organized their filament system in the normal or hypertensive lung reflects in part the need to apply special techniques to preserve antigcnic structures for high resolution studies. In sections of lung vessels examined by transmission electron microscopy only the filament network of actin are visible. Typically, actin filaments are expressed in the leading edge of migrating cells and in the subnuclear region of cells aligning in the vessel wall. The use of special fixation and low temperature processing techniques to preserve intermediate filament and myofilament structures will allow us to establish the relevant proteins, including the expression of actin isoforms, intermediate filament proteins, and different forms of myosin. Actin is usu- ally abundant in the filaments of all cells, and present with myosin in the myofilaments of SMC, where the y-smooth muscle actin isoform predominates. As in systemic vessels, it is likely that different lung vascular cells express different intermediate filaments composed of either vimentin or desmin $(60,61)$. In several species, there is evidence of heterogeneity of myosin expression in vascular cells (62), as for example in the medial cells of large and small muscular arteries which express smooth muscle myosin, and in those of large elastic arteries which express nonmuscle myosin. At sites other than lung, there is evidence that the filaments of vascular contractile cells change in response to injury (63) and, in lung, evidence of such changes in interstitial cell populations $(47,64,65)$. Whether 
similar changes occur in the vessels of the lung is not known. Nor is it known whether in injured microvessels, as in large arteries, it is the cytoskeletal or contractile filaments that increase (66), in addition to increase in matrix protein secretion. From several studies there is emerging evidence that lung cells modulate their expression of contractile proteins in response to growth mediators. How this is linked to functional demands remains to be determined. Following their development in the wall of distal lung vessels, contractile cells can migrate through disruptions in the endothelium to occlude the lumen, by cell proliferation and collagen synthesis.

\section{CONCLUSIONS}

- The walls of the pre- and postcapillary microvessel segments thicken and develop contractile cells in response to the injuries leading to the development of pulmonary hypertension. This site of restriction to blood flow is the structural basis of maintained rise in pressure. Wall remodeling is progressive and is the result of cell hypertrophy and hyperplasia in response to growth mediators synthesized in excess of the need for cell replacement. New contractile cells develop from precursor cells - intermediate cells and possibly pericytes within the vessel wall, and interstitial fibroblasts recruited to it. The organization of these cells into layers within the wall is effected by formation of basement membranes and elastic laminae. This stage is associated with the expression of proteins responsible either for organization of the supporting cell matrix or for the filaments associated with cell contraction. This converts capillary-like segments adjacent to the capillary bed into thick-walled resistance vessels.

\section{REFERENCES}

1. Jones R, Reid L. Vascular remodeling in the clinical and experimental pulmonary hypertensions. In: Bishop JE, Reeves J, Laurent GJ, editors. Pulmonary vasculature remodeling. London, Portland Press. In press

2. Geggel RL, Reid L. Structural basis of PPHN. In: Clinics in perinatology. Phillips JB, 1984; 525-549

3. Heath D, Heimholz HF, Burchell HB, DuShane JW, Edwards JE. Graded pulmonary vascular changes and hemodynamic findings in cases of atrial and ventricular septal defect and patent ductus arteriosus. Circulation 1958; 18: 1155

4. Heath D, Smith P, Harris P, Yacoub M. Plexiform lesion in bronchopulmonary anastomosis. BrJDis Chest 1988; 82:294-299

5. HosodaY. Pathology of pulmonary hypertension: A hu- man and experimental study. Pathol Intern 1994; 44:241267

6. Jones R, Zapol WM, Reid L. Pulmonary artery remodeling and pulmonary hypertension after exposure to hyperoxia for 7 days. A morphometric and hemodynamic study. Am J Pathol 1984; 117: 273-285

7. Jones R, Tomashefski JF, Kobayashi K, Zapol WM, et al. Pulmonary vascular pathology: human and experimental studies in acute respiratory failure. In: Acute respiratory failure. Lung biology in health and disease series. New York, Marcel Dekker, vol 24, 1985; 23-160

8. Jones R, Zapol W, Reid L. Oxygen toxicity and restructuring of pulmonary arteries - A morphometric study. The response to 4 weeks' exposure to hyperoxia and return to breathing air. Am J Pathol 1985; 212-223

9. Meyrick BO, Reid L. The effect of continued hypoxia on rat pulmonary arterial circulation: An ultrastructural study. Lab Invest 1987; 38: 188-200

10. Parks WC, Mecham RP, Crouch EC, et al. Response of lobar vessels to hypoxic pulmonary hypertension. Am Rev RespirDis 1989; 140: 1455-1457

11. Stenmark KR, Fasules J, Hyde DM, et al. Severe pulmonary hypertension and arterial adventitial changes in newborn calves at $4300 \mathrm{~m}$. JApplPhysiol 1987; 62: 821-830

12. Gibbons GH, Dzau VJ. The emerging concept of vascular remodeling. NEnglJMed 1994; 330: 1431-1438

13. Langille BL, O'Donnell F. Reductions in arterial diameter produced by chronic decrease in blood flow are endothelium dependent. Science 1986; 231: 405-407.

14. Reid L, Fried R, Geggel R, Langleben D. Anatomy of pulmonary hypertensive states. In: Bergofsky EH, editor. Abnormal pulmonary circulation, contemporary issues in pulmonary disease. New York, Churchill Livingstone, 1986; 221-263

15. Langleben D, Jones R. Organization and role of lung cells. In: Biebuyck JF, Lynch C, Maze M, Saidman LJ, Yaksh TL, Zapol WM, editors. Anesthesia: biologic foundations, Vol II (Part 3) The respiratory system. New York, Raven Press. In Press

16. Elliot FM, Reid L. Some new facts about the pulmonary artery and its branching pattern. Clin Radiol 1965; 16: 193-198 
17. Reid L. Structural and functional reappraisal of the pulmonary artery system. Scientific basis of medicine annual review. London, The Athlone Press, 1968; 289-307

18. Reid L. The pulmonary circulation: remodeling in growth and disease. Am Rev Respir Dis 1979; 119: 531-546

19. Hislop A, Reid L. Fetal and childhood development of the intrapulmonary veins in man: branching pattern and structure. Thorax 1973; 28: 313-319

20. Jones R. Ultrastructural analysis of contractile cell development in hyperoxic pulmonary hypertension: Fibroblasts and intermediate cells selectively reorganize nonmuscular segments. AmJPathol 1992; 141: 1491-1505

21. Davies P, Burke G, Reid L. The structure of the wall of the rat intraacinar pulmonary artery: An electron rnicroscope study of microdissected preparations. Microvasc Res 1986; 32: 50-63

22. Jones R. Role of interstitial fibroblasts and intermediate cells in microvascular wall remodeling in pulmonary hypertension. Eur Respir J 1993; 3: 569-575

23. Meyrick BO, Reid L. Ultrastructural features of the distended pulmonary arteries of the normal rat. Anat Rec 1979; 193: 71-98

24. Skalli O, Pelte MF, Peclet MC, Gabbiani G, Guliotta P, Bussolati G, et al. Smooth muscle actin, a differentiation marker of smooth muscle cells, is present in microfilamentous bundles of pericytes. / Histochem Cytochem 1989; 37: 315-321

25. Sims DE. Recent advances in pericyte biology. Can J Cardiol 1991;7:431-443

26. Herget J, Palechek F. Experimental chronic pulmonary hypertension. Int Rev Exp Pathol 1978; 18: 347-406

27. Boxt LM, Katz J, Liebovitch LS, Jones R, Esser P, Reid L. Fractal analysis of pulmonary arteries: The fractal dimension is lower in pulmonary hypertension. $J$ Thorac Imaging 1994; 9: 8-13

28. Zapol WM, Snider MT. Pulmonary hypertension in severe acute respiratory failure. NewEnglJMed 1977; 296: $476-480$

29. Tomashefski JF Jr, Davies P, Boggis C, Greene R, et al. The pulmonary vascular lesions of the adult respiratory distress syndrome. AmJPathol 1983; 112: 112-126
30. Gore RG, Jones R. Pulmonary vascular reactivity in hyperoxic pulmonary hypertension in the rat. $J$ Appl Physiol 1988; 65: 2617-2623

31. Colefsky JT, Jones RC, Reid LM, Evans JN. Mechanical properties and structure of isolated pulmonary arteries remodeled by chronic hyperoxia. Am Rev Respir Dis 1987; 136: $388-394$

32. Hu LM, Jones RC. Injury and remodeling of pulmonary veins by high oxygen. A morphometric study. AmJPathol 1989; 134: 253-262

33. Jones R, Adler C, Farber F. Lung vascular cell proliferation in hyperoxic pulmonary hypertension and on return to air: $\left[{ }^{3} \mathrm{H}\right]$ Thymidine pulse-labeling of intimal, medial and adventitial cells in microvessels and at the hilum. Am Rev Respir Dis 1989; 140: 1471-1477

34. Zimmerman GA, LorantDE, Mclntyre TM, Prescott SM. Juxtacrine intercellular signaling: another way to do it. Am J Respir Cell Mol Biol 1993; 9: 573-577

35. Horinouchi H, Wang CC, Shepherd K, Jones R. TNFa gene expression is induced in rat PAMs in early and chronic stages of hyperoxia-induced lung injury [abstract]. Am J Respir Crit Care Med 1995; 151: 734A

36. Jacobson M, Wang CC, Horinouchi H, Shepherd K, Jones R. Regulation of PDGF-BB protein expression by PAMs in pulmonary hypertension [abstract]. Am J Respir Crit Care Med 1995; 151: 734A

37. Perkett, EA, Pelton RW, Meyrick B, Gole LI, Miller DA. Expression of transforming growth factor-p mRNAs and proteins in pulmonary vascular remodeling in the sheep air embolization of pulmonary hypertension. Am J Respir Cell Mol Biol 1994; 11: 16-24

38. Pelton RW, Johnson MD, Perkett EA, Gold LI, Moses HL. Expression of transforming growth factor- $p$, $-\mathrm{p}$, and -P, mRNA and protein in the murine lung. Am J Respir Cell Mol Biol 1991; 5: 522-530

39. Powell P, Wang CW, Jones R. Differential regulation of the genes encoding platelet-derived growth factor receptor and its ligand in rat lung during microvascular and alveolar wall remodeling in hyperoxia. Am J Respir Cell Mol Biol 1992; 7: 278-285

40. Powell P, Klagsbrun M, Abraham JA, Jones R. Eosinophils expressing heparin-binding EGF-like growth factor mRNA localize around lung microvessels in pulmonary hypertension. AmJPathol 1993; 143: 784-793 
41. Stenmark KR, Dempsey EC, Badesch DB, Frid M, Mecham RP, Parks WC. Regulation of pulmonary vascular wall cell growth: developmental and site-specific heterogeneity. EurRespirRev 1993; 3: 629-637

42. Wang CC, Horinouchi H, Shepherd K, Jones, R. Regulation of basic fibroblast growth factor ligand (bFGF) and receptor (FGFR) gene expression in pulmonary hypertension and localization of protein [abstract]. Am JRespir Crit Care Med 1995; 151: 734A

43. Wang N, Butler JP, Ingber DE. Mechanotransduction across the cell surface and through the cytoskeleton. Science 1993; 260: 1124-1127

44. Ingber DE, Dike L, Hansen L, Karp S, Liley H, Maniotis A, et al. Cellular tensegrity: exploring how mechanical changes in the cytoskeleton regulate cell growth, migration, and tissue pattern during morphogenesis. Int Rev Cytol 1994; 94: 173-224

45. Jones R, Rock K, Fujiwara K. Development of contractile cells in pulmonary hypertension - differential expression of smooth muscle myosinby precursor cells [abstract]. Am JRespir Crit Care Med 1994; 149: 824A

46. Dawes KE, Peacock AJ, Gray AJ, Bishop JE, Laurent G. Characterization of fibroblast mitogens and chemoattractants produced by endothelial cells exposed to hypoxia. Am JRespir Cell Mol Biol 1994; 10: 552-559

47. Adler $K B$, Low RB, Leslie KO, Mitchell J, Evans JN. Contractile cells in normal and fibrotic lung. Lab Invest 1989; 60: 473-485

48. Kapanci Y, Assimocopoulos A, Zwahlen A, Gabbiani G. "Contractile interstitial cells" in pulmonary alveolar septae: a possible regulator of ventilation/perfusion ratio? / Cell Biol 1974; 60: 375-392

49. Zhang K, Rehter MD, Gordon D, Phan SH. Myofibroblasts and their role in lung collagen gene expression during pulmonary fibrosis. AmJPathol 1994; 145: 114-125

50. Rhodin JAG, Fujita H. Capillary growth in the mesentery of normal young rats. Intravital video and electron microscopy images. / Submicros Cytol Pathol 1989; 21: $1-34$

51. Crouch E, Martin G, Brodie J. Basement membranes. In: Crystal R, West G, Cherniak N, Weibel E, editors. The lung: scientific foundations. New York, Raven Press, 1991; 421-437
52. Lipke D, Arcot S, Gillespie M, Olson J. Temporal alterations in specific basement membrane components in lungs from monocrotaline-treated rats. Am JRespir Cell Mol Biol 1993; 9: 418-428

53. Yurchenco PD, O'Rear J. Supramolecular organization of basement membranes. In: Rohrbach DH, Timpl R, editors. Molecular and cellular aspects of basement membranes. Academic Press, 1993; 19-47

54. Vlodavsky I, Bar-Shavit R, Korner G, Fuks Z. Extracellular matrix-bound growth factors, enzymes, and plasma proteins. In: Rohrbach DH, Timpl R, editors. Molecular and cellular aspects of basement membranes. Academic Press, 1993; 327-343

55. Nathan C, Sporn M. Cytokines in context. / Cell Biol 1991; 113: 981-986

56. Fulmer H, Sheetz J, Narkates A. Oxytalin connective tissue fibers: a review. J Oral Pathol 1974; 3: 291-316

57. Gabrovska M, Vancov V. Secretory features of chondrocytes related to morphogenesis of the elastic elements in the auricular cartilage. Ada Morphol Acad Sci Hung 1982; 30: 127-134

58. Sakai LY, Keene DR, Engvall E. Fibrillin, a new 350kDa glycoprotein, is a component of extracellular microfibrils. J Cell Biol 1986; 103: 2499-2509

59. Mecham RP. Laminin receptors. Annu Rev Cell Biol 1991; 7: 71-91

60. Osborn M, Caselitz J, Weber K. Heterogeneity of intermediate filament expression in vascular smooth muscle: A gradient of desmin positive cells from the rat aortic arch to the level of the arteria iliaca communis. Differentiation 1981; 20: 196-202

61. Schmid E, Osborn M, Rungger-Brandle E, Gabbiani G, Weber K, Franke WW. Distribution of vimentin and desmin filaments in smooth muscle tissue of mammalian and avian aorta. Exp Cell Res 1982; 137: 329-340

62. Larson D, Fujiwara K, Alexander RW, Gimbrone M. Myosin in cultured vascular smooth muscle cells: Immunoflourescence andimmunochemical studies of alterations in antigenic expression. J Cell Biol 1984; 99: 1582-1589

63. Kocher O, Skalli O, Bloom WS, Gabbiani G. Cytoskeleton of rat aortic smooth muscle cells. Normal conditions and experimental intimal thickening. Lab Invest 1984; 50: $645-652$ 
64. Malmqvist U, Armer A. Isoform distribution and tissue contents of contractile and cytoskeletal proteins in hypertrophied smooth muscle from rat portal vein. CircRes 1990; 66: 832-845

65. Sappino AP, Schurch W, Gabbiani G. Differentiation repertoire of fibroblastic cells: expression of cytoskeletal proteins as marker of phenotypic modulations. Lab Invest 1990; 63: 144-161

66. Berner P, Somlyo AV, Somlyo AP. Hypertrophy-induced increase of intermediate filaments in vascular smooth muscle. JCellBiol 1981; 88: 96-101

Received 23 May 1995

Accepted 5 July 1995

Address for correspondence:

Dr Rosemary C. Jones

Department of Anesthesia Massachusetts General Hospital 149 Thirteenth Street Charlestown, MA 02129 